\title{
How Beautiful Upon the Mountains
}

Isaiah 52:7-10

Alan SAnderson

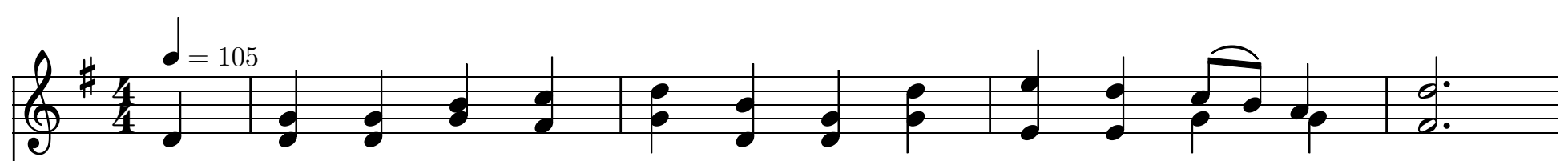

How beau - ti - ful up - on the moun-tains are the feet of Him

Thy watch-men shall lift up the voice, with one voice shall they sing,

Ye waste-lands of Je - ru - sa - lem, the Lord doth com - fort thee.

The Lord doth bear his ho - ly arm for all the world to see,
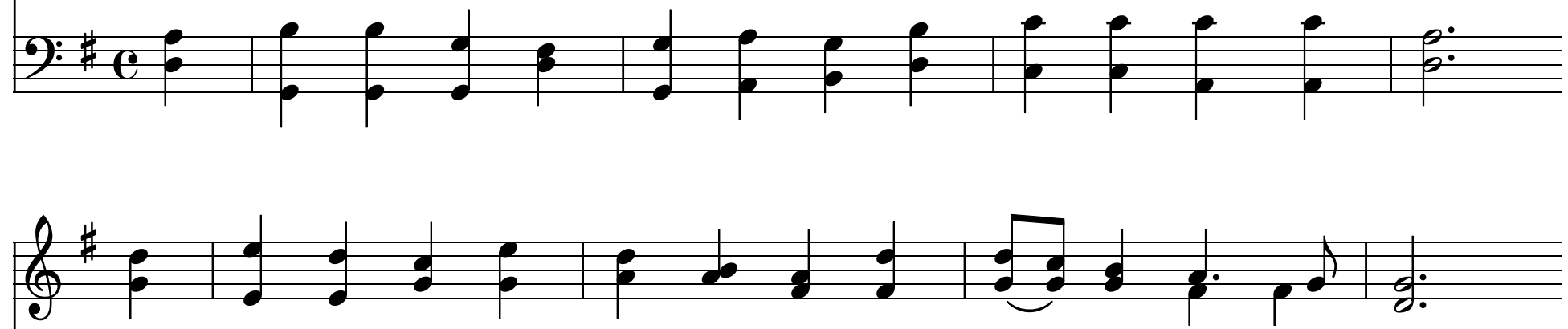

That bring - eth peace and pub - lish - eth sal - va - tion from our sin.

For we shall all see eye to eye when $\mathrm{Zi}$ - on Thou dost bring.

Now break forth in - to joy and sing, Je - ru-sa-lem is re -deemed.

And all the ends of earth shall know sal - va - tion is of Thee.

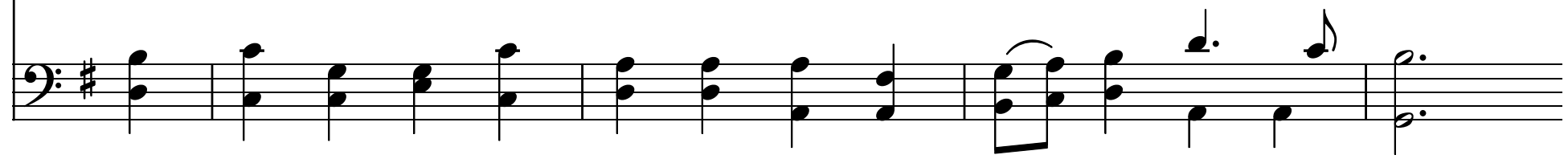

